\title{
As memórias e a instabilidade genérica: considerações acerca dos diferentes modos de inserção do tempo no processo constitutivo de memórias de professoras
}

DOl: http://dx.doi.org/10.21165/el.v50i1.2898

\section{Orasir Guiherme Teche Cális ${ }^{1}$}

\section{Resumo}

Partindo do famoso postulado de Bakhtin (2003), segundo o qual os gêneros do discurso são "tipos relativamente estáveis de enunciado" (BAKHTIN, 2003, p. 262), este artigo procura mostrar, a partir das ocorrências da palavra tempo, em um conjunto de textos memorialísticos produzidos por professoras-alfabetizadoras, de que modo se encontra inscrita nessa mesma definição, como outra face de uma mesma moeda, a percepção dos gêneros discursivos como sendo também constitutivamente instáveis, isto é, marcados muito mais pela abertura do que pelo fechamento de suas fronteiras. Isso se deve às diferentes formas de apropriação e condições de produção de um dado gênero, bem como às diferentes formas de diálogo que o(a) escrevente estabelece com outros gêneros discursivos, mas também em função de uma particularidade do gênero em questão: o diálogo estabelecido entre o presente e o passado.

Palavras-chave: gêneros discursivos; memória; instabilidade genérica; tempo; ensino de língua materna.

1 Professor da rede pública municipal de Ensino Básico, Cubatão, São Paulo, Brasil; bionicalis@uol.com.br; https://orcid.org/0000-0002-2963-1493 


\section{Mémoires et instabilité générique: réflexions sur les differéntes manières d'insérer le temps dans les processus constitutif de la mémoire des ensegnants}

\section{Résumé}

Prenant comme point de départ le fameux postulat de Bakhtine (2003), selon lequel les genres de discours sont des «types d'énoncés relativement stables » (BAKHTINE, 2003, p. 262), cet article cherche à montrer, à partir des occurrences du mot temps, dans un ensemble de textes mémorialistes produits par les alphabétiseurs, comment s'inscrit-il dans cette même définition, comme un autre côté de la même médaille, la perception des genres discursifs comme étant aussi constitutivement instables. C'est-à-dire marqués beaucoup plus par l'ouverture que par la fermeture de ses frontières, qui tient aux différentes formes d'appropriation et aux conditions de production d'un genre donné, ainsi qu'aux différentes formes de dialogue que l'scripteur établit avec d'autres genres discursifs, mais aussi à cause d'une particularité du genre en question: le dialogue établi entre le présent et le passé.

Mots-clés: genres discursifs; mémoire; instabilité générique; temps; enseignement de la langue maternelle.

\section{Introdução}

Minha experiência como professor permite observar que, em nossas escolas, a moda de ensino dos gêneros do discurso fez, e ainda faz, prevalecer a consideração do produto em detrimento de seus processos de constituição. Em outras palavras, dadas as condições em que se realiza o trabalho do professor, o ensino de um gênero discursivo em nossas salas de aula (quando ocorre) procura focalizar, ao que parece, tão-somente se os textos produzidos pelos alunos corresponderam aos modelos apresentados pelos professores, 0 que se traduz, na maioria dos casos, na mera verificação dos aspectos formais presentes nesses textos. Tal hipótese baseia-se nas percepções já levantadas por Fiorin (2008, p. 60), para quem:

Depois que os Parâmetros Curriculares Nacionais estabeleceram que o ensino de Português fosse feito com base nos gêneros, apareceram muitos livros didáticos que veem o gênero como um conjunto de propriedades formais a que o texto deve obedecer. $\mathrm{O}$ gênero é, assim, um produto, e seu ensino torna-se, então, normativo.

Esse modo de apropriação do que Bakhtin (2003, p. 262) chamou de "tipos relativamente estáveis de enunciado", modalização a cuja inobservância o discurso pedagógico ainda paga pesado tributo, põe em cena uma característica essencial presente em qualquer consideração que se faça a respeito dos gêneros discursivos: a tensão existente entre 
aquilo que é estável - e que, por assim dizer, define um momento específico de seu processo constitutivo - e aquilo que aponta para a natureza intrinsecamente instável inerente a esse mesmo processo. Com efeito, o filósofo russo observa que "cada campo de utilização da língua elabora seus tipos relativamente estáveis de enunciado, os quais denominamos gêneros do discurso" (BAKHTIN, 2003, p. 262, grifo do autor). Tal definição, ao modalizar os elementos estáveis presentes no processo de produção dos gêneros discursivos, não deixa de apontar, como pressuposto, para aspectos que, desde sempre inscritos nos gêneros, poderíamos chamar - ainda que com certa cautela - de constitutivamente instáveis. Assim, essa dinâmica constitutiva parece evidenciar uma espécie de tensão entre o que permanece e o que escapa, principalmente aos olhares do discurso pedagógico, no processo constitutivo dos gêneros discursivos.

Vários são os autores que apontam para essa natureza predominantemente fluida, mais processo do que produto, dos gêneros do discurso. Fiorin (2008, p. 61), por exemplo, faz questão de pontuar o quanto essa percepção já se encontrava formulada pelo próprio Bakhtin, a quem interessavam "menos as propriedades formais dos gêneros do que a maneira como eles se constituem". O autor, ao destacar a relação intrínseca entre gêneros e esferas da atividade humana, ressalta ainda que "o gênero une estabilidade e instabilidade, permanência e mudança" (FIORIN, 2008, p. 69). Depreende-se, desse modo, a extrema flexibilidade que preside, sempre, o processo de produção de um dado gênero discursivo, o que nos obriga a atentar para seus modos de constituição, e não para a suposta - e relativa - rigidez de suas formas.

Faraco (2009, p. 127), por sua vez, observa que Bakhtin, ao se referir aos gêneros como sendo tipos relativamente estáveis, "está dando relevo, de um lado, à historicidade dos gêneros; e, de outro, à necessária imprecisão de suas características e fronteiras". Tal passagem destaca, a um só tempo, a importância dos eventos históricos para o processo de constituição dos gêneros, o que nos possibilita afırmar que estes não se constituem no vazio, colocando em evidência, novamente, a fluidez característica dessas formas relativamente estáveis do dizer, que precisam "ser abertas à contínua remodelagem, tendo de ser capazes de responder ao novo e à mudança" (FARACO, 2009, p. 127).

Algumas questões, no entanto, precisam ser colocadas: o que seria, exatamente, essa instabilidade presente nos gêneros, de que sua historicidade é caudatária? Como seria possível apreender essa inscrição do instáve/ marcada, como sua contraparte constitutiva, nos processos que regem a produção escrita de um gênero discursivo? E mais: que razões explicariam essa instabilidade? Além disso, de que modo a consideração de tais aspectos, se pertinente, poderia tornar-se produtiva nos debates que envolvem o ensino de língua materna, mormente no que se refere à didática de ensino dos gêneros?

Como já dito acima, os gêneros do discurso não são apenas "tipos relativamente estáveis de enunciado" (BAKHTIN, 2003, p. 262), mas, sobretudo, práticas sóciodiscursivas 
marcadas por uma constitutiva instabilidade, decorrente, do ponto de vista que assumo, dos diferentes modos de apropriação de que se valem os(as) falantes ou os(as) escreventes durante seu processo de produção.

Partindo, pois, dessa dinâmica entre o que é relativamente estável e o que, em suas dobras, constitui-se de forma instável, tal percepção se baseia no fato de que o processo de constituição dos gêneros - ainda que estes tenham uma existência a priori, na medida em que todo gênero já foi historicizado pelo uso - não existe independentemente de um sujeito (falante ou escrevente) que deles se apropria a partir de condições de produção específicas, as quais atuam, de forma determinante, sobre esse mesmo processo, instabilizando-o.

Dito isto, ao ancorar-se na análise das várias formas de inscrição da palavra tempo em textos memorialísticos produzidos por professoras alfabetizadoras em um curso de formação, o objetivo deste trabalho será depreender um dos muitos aspectos constitutivos dessa instabilidade genérica, tomando-a como ponto de partida privilegiado para a análise dos diferentes modos de inserção temporal no processo de escrita do gênero por elas produzido, a partir de um funcionamento que considero constitutivo e relativamente estável: o diálogo ${ }^{2}$ entre o passado e o presente.

Nesta perspectiva, ao colocar em evidência a extrema heterogeneidade que regula 0 processo de constituição dos gêneros discursivos, particularmente no que se refere às relações temporais, as análises visam apontar para um dos modos de percepção da inevitável instabilidade presente nesse mesmo processo, por meio da consideração das diferentes nuanças a que a palavra tempo, para além de sua circunscrição dicionária, possui. Dito de outro modo, em suas diversas formas de reinscrição, toda e qualquer palavra carrega os vestígios de uma história constitutivamente instável - o que é possível apreender mediante a observação de seus diferentes usos e sentidos -, bem como das próprias inflexões impostas por determinado gênero discursivo.

Assim, embora em relação ao conteúdo temático das memórias, isto é, ao seu universo de sentido, a recorrência por parte das escreventes à palavra tempo tenha representado um aspecto relativamente estável na escrita das memórias, defendo que a percepção do instável, no que se refere a essa mesma presença, marca-se no acontecimento ${ }^{3}$

2 Faço referência, aqui, às relações de sentido estabelecidas entre dois ou mais enunciados, ou seja, ao fato de todo enunciado fazer remissão a enunciados já ditos e/ou escritos, aspecto que coloca em destaque sua historicidade.

3 Utilizo esta palavra, aqui, não em sua acepção comum de evento ou fato ocorrido, mas sim no sentido de novidade capaz de romper a aparente impermeabilidade de uma estrutura, de uma previsibilidade, na medida em que "todo enunciado é intrinsecamente suscetível de tornar-se outro, diferente de si mesmo, [deslocando-se] discursivamente de seu sentido para derivar para um outro" (PÊCHEUX, 2002, p. 53). 
que representou seus diferentes modos de reaparição no processo de escrita, ou seja, nas diferentes formas a partir das quais essa palavra, ao imprimir-se no processo de escrita do referido gênero, carreou diferentes sentidos, diferentes entoações, isto é, variegados valores atribuídos ao que foi produzido pelas escreventes, o que acarretou, como consequência, diferentes modos de relação entre o passado e o presente. No limite, vislumbro neste aspecto, que põe em relevo a necessária dimensão ideológica da palavra, "carregada de diferentes conteúdos semânticos e axiológicos" (BAKHTIN, 2014, p. 96), um modo privilegiado de percepção da instabilidade no processo de escrita das memórias.

\section{Fundamentos teóricos}

O tempo é plural. Inconstante e fluido, de natureza imutável e irredutível a apreensões furtivas, "não havendo nele lugares mortos, imóveis, paralisados" (BAKHTIN, 2003, p. 245), ele parece corresponder ao domínio por excelência do instável. A luta contra o tempo, que sempre escapa por entre os dedos, parece refletir-se nas vãs tentativas de enclausurá-lo em delimitações, cujo objetivo é torná-lo menos fugidio e mais perene à nossa frágil condição humana. Força invisível, infensa à facilidade das imagens rápidas que obliteram o singular e o imperceptível, sua extrema heterogeneidade permite que possamos, somente, rastrear seus indícios, espalhados sobejamente a nossa volta: numa folha que desenha no ar o movimento de sua queda, nas cãs que aos poucos se misturam aos cabelos, tornando-os grisalhos, ou no fluxo de um rio a seguir seu curso aparentemente eterno.

Já nesta exemplificação das diferentes formas de manifestação do tempo, é possível depreender sua presença ao menos em sua dimensão física, a qual, para Benveniste (1989, p. 70), caracteriza-se por uma "duração infinitamente variável que cada indivíduo irá medir ao sabor de suas emoções e ao ritmo de sua vida interior". Trata-se, aqui, de um princípio de instabilidade marcado na própria visão assumida pelo autor, já que a dimensão do tempo, se tão-somente individualizada e restrita às idiossincrasias humanas, reproduziria ad infinitum suas diversas formas de percepção e o próprio tempo seria reduzido às impressões isoladas de cada indivíduo. É neste sentido que o autor, ao estabelecer uma distinção fundamental entre duas dimensões temporais - uma individualizada, quase inacessível, e outra mais passível de circunscrições -, irá propor a ideia de um tempo crônico.

Para o autor, a partir de tal perspectiva, o que chamamos tempo é a continuidade "na qual se dispõem em série esses blocos distintos que são os acontecimentos. Estes não são o tempo, na medida em que estão no tempo" (BENVENISTE, 1989, p. 70). Aqui, o tempo pode ser mensurado, cercado, dividido. Tal separação, fundamental, ao ancorar o homem em um lugar dentro desse fluxo (in)constante - o que, de outro modo, lançá-lo-ia em permanente estado de indefinição -, fornece-lhe pontos de referência a nos indicar "onde 
nos encontramos na vastidão da história, qual é o nosso lugar entre a infinita sucessão de acontecimentos que parecem não distinguir homens e coisas" (BENVENISTE, 1989, p. 72).

No entanto, longe de ser um espaço de permanência e fixidez, essa forma de mensurar o tempo também encontra seus limites e instabilidades na própria não coincidência entre as tentativas de fixar o tempo - mediante um calendário, por exemplo - em comparação com outras formas de manifestação da experiência humana. Para Benveniste (1989, p. 73), "é por meio da linguagem que se manifesta a experiência humana de tempo". A singularidade desta forma de inserção temporal situa-se no fato de que, mediante o estabelecimento de um eixo axial ancorado no presente da enunciação, instauram-se, como consequência, as demais oposições temporais: nomeadamente o passado e o presente.

Para o autor, "o momento no qual o evento não é contemporâneo do discurso, deixou de ser presente e deve ser evocado por meio da memória" (BENVENISTE, 1989, p. 73). E continua: "e aquele no qual o evento ainda não está presente, torna-se futuro e surge em prospecção." (BENVENISTE, 1989, p. 74). Depreende-se desta passagem o quão marcados pela instabilidade encontram-se esses tempos engendrados pelo presente, na medida em que dependem de uma estabilidade situada num instante preciso da enunciação, isto é, aquele em que acontecimento e discurso coincidem. Assim, porquanto o passado não existe enquanto tal - já que não é a não ser por meio de recriação da linguagem -, nem o futuro apresenta qualquer espessura passível de apreensão - uma vez que, também, ainda não existe senão prospectivamente -, pode-se perceber de que forma o instável se inscreve principalmente naqueles gêneros discursivos, por exemplo, as memórias, em cujo processo de constituição o diálogo entre o passado e o presente é incontornável.

Bakhtin (2003), ao deter-se sobre a obra do poeta alemão Goethe, também fez importantes observações sobre a questão do tempo. Para o autor, sua movência revelase em sua diversidade de manifestação, no modo como fragmentos de tempo surgem "como remanescentes ou relíquias dos diferentes graus e formações do passado e como embriões de um futuro mais ou menos distante" (BAKHTIN, 2003, p. 229). Por esta passagem, percebe-se que o poder do tempo também é prospectivo, de vez que os vestígios de sua presença não apenas revelam a existência de um passado em relação a um presente, mas também deste em relação a um futuro. Espaço de confluências, de vozes que se cruzam, o tempo é constituído de "um passado criativamente eficaz, determinando o presente e fornecendo com este uma direção também para o futuro, em certa medida antecipando-o" (BAKHTIN, 2003, p. 235).

O tempo também é movimento que possibilita observar o próprio homem e sua imersão na história. Para o autor, aqui se encontram os "vestígios visíveis da criação do homem, vestígios de suas mãos e da sua inteligência: [nas] cidades, ruas, casas, obras de arte, 
organizações sociais, etc." (BAKHTIN, 2003, p. 225). Este modo de situar o tempo, não o desvinculando dos lugares em que se pode perceber sua presença, desvela sua contraparte imprescindível e inseparável: sua relação com o espaço.

Com efeito, ao abordar aspectos romanescos a partir do conceito de cronotopo, o filósofo russo observa que "em todos os seus momentos essenciais o tempo está localizado em um espaço concreto, marcado nele" (BAKHTIN, 2003, p. 245), não sendo possível, desse modo, observá-los de forma distinta, isolada, uma vez que se encontram integralizados num todo orgânico e indissolúvel. Para o autor, essa interpenetração mútua entre o espaço e o tempo, ao condensar mundo e história, somente foi possível porque "o ambiente deixou de ser parte de uma natureza abstrata e parte de um mundo indefinido [...] e o acontecimento deixou de ser um fragmento do tempo igualmente indefinido" (BAKHTIN, 2003, p. 254).

Essa capacidade de ler o espaço no tempo revela-se bastante produtiva, tendo em vista que o conjunto de textos que compõem nosso corpus - memórias produzidas por professoras - não revelou apenas a relação inextricável entre o passado e o presente materializada na escrita de seus textos, mas também a materialização desse diálogo constitutivo das memórias nos espaços concretizados por esse tempo. Em outras palavras, o tempo das memórias, longe de constituir algo estático, vazio e imóvel, é saturado de ambiências, de lugares e de pontos nos quais as lembranças resgatadas vão se construindo e ganhando corpo, adensando-se juntamente com a imagem dos espaços recriados pelo tempo.

Para Amorim (2008, p. 105), o conceito de cronotopo, ao ligar-se a um modo de produção da história, "designa um lugar coletivo, espécie de matriz espaço-temporal de onde as várias histórias se contam ou se escrevem". Assim, na medida em que se relaciona aos gêneros, a uma inscrição mais coletiva, mais pública, a autora identifica esse conceito a uma visão capaz de definir o ser humano "inteiramente pela esfera social, num tempo coletivo e único, partilhado por todos em esferas comuns de atividade" (AMORIM, 2008, p. 105-106).

Destaco da passagem acima dois aspectos: a) as memórias produzidas pelas professoras, como a própria marca de plural indica, carregam, em seu processo constitutivo, os vestígios de várias vivências que se contam, de várias vozes que se cruzam em espaços partilhados de forma gregária, comum; b) principalmente em função da maneira como as esferas sociais se organizam, e se entrecruzam, elaborando, assim, seus tipos relativamente estáveis de enunciado, diria que esses vestígios da presença humana encontram-se desde sempre diluídos (e instabilizados) nos gêneros discursivos que o homem produz: trata-se, pois, do homem mergulhado no tempo e inscrito na história. 


\section{Metodologia de análise}

Neste artigo, tomo como ponto de partida a análise de 84 textos de cunho memorialístico produzidos por professoras alfabetizadoras, no ano de 2006, como atividade inicial de um curso de capacitação intitulado Letra e vida. Aplicado exatamente nos mesmos moldes do antigo Programa de Formação de Professores Alfabetizadores (PROFA), o Letra e vida destinava-se especialmente a professores e professoras que lecionavam nas séries iniciais da Educação Infantil e, também, no Ensino Fundamental'.

Não obstante seu público-alvo ser composto, em sua grande maioria, por professoras alfabetizadoras, tratava-se de um curso voltado a qualquer profissional da educação interessado no aprimoramento de seus conhecimentos, mormente no que concerne ao processo de ensino e aprendizagem referente a essa etapa da escolarização formal.

A fim de tentar apreender a instabilidade genérica presente no processo de constituição das memórias ali produzidas, bem como a diversidade quanto aos seus diferentes modos de apropriação, adotei como recurso metodológico a análise comparativa dos textos que compõem o corpus selecionado, colocando em relevo não somente as semelhanças que, de fato, eles possuem, mas, sobretudo, procurando evidenciar, mediante tal método, as diferenças por vezes sutis que os tornaram exemplos de textos marcados por uma profunda singularidade do ponto de vista discursivo.

Defendo, portanto, que um mesmo gênero discursivo pode possuir diferentes configurações textuais (diferentes regularidades), a depender das relações intergenéricas (BAKHTIN, 2003) marcadas em seu processo de escrita, as quais poderão ser vistas como indícios da relação do sujeito com a linguagem. Tal orientação metodológica, fundamentando-se nos trabalhos de Ute Heidmann (2010, p. 63), traz para o âmbito deste artigo reflexões inscritas em uma perspectiva de análise que concebe a noção de texto "como discurso [que leva] em consideração os princípios epistemológicos da comparação".

Para esta autora, que se utiliza desses princípios para a análise comparada de textos literários e para a análise de traduções, "o reconhecimento da diferença é frequentemente negligenciado em favor da focalização imediata e quase exclusiva sobre a pesquisa do semelhante [...] e, por extensão, do universal" (HEIDMANN, 2010, p. 64), o que, em outras palavras, significa dizer que, embora seja frequente, por parte do analista, a percepção de aspectos comuns em textos postos sob análise, "nada nos obriga a generalizar esse traço

4 Ponto de partida do processo de aprendizagem, a Educação Infantil, correspondente à educação pré-escolar anterior ao ensino obrigatório, é destinada às crianças entre 0 e 5 anos de idade; já o Ensino Fundamental, que se estende do $1^{\circ}$ ao $9^{\circ}$ ano, corresponde a uma das etapas obrigatórias da escolarização formal, abarcando os alunos cuja idade, em geral, vai dos 6 aos 14 anos. 
para constituir universais" (HEIDMANN, 2010, p. 64). A autora também alerta para o fato de que essa busca desenfreada pelo que é semelhante e universal impede não somente o reconhecimento e a exploração do que é diferente, mas também impossibilita que se tome "consciência da necessidade de conceber o procedimento comparativo como um ato de construção" (HEIDMANN, 2010, p. 66). Dizendo de outro modo, a opção pela diferenciação deve subsumir a construção de um nível axial comparativo "suficientemente pertinente e complexo para considerar, ao mesmo tempo, o traço comum percebido e as diferenças fundamentais dos fenômenos a serem comparados" (HEIDMANN, 2010, p. 66).

Embora a autora utilize a metodologia acima para a análise de um corpus diferenciado ${ }^{5}$ em relação às memórias com as quais trabalho, creio que sua utilização aqui se justifica em função, principalmente, de duas razões: a) tendo em vista que se trata de um corpus extenso, essa metodologia permite, mediante a metodologia comparativa, que se observem as menores variações entre os textos analisados, de modo a identificar os agrupamentos discursivos que apresentam características genéricas comuns, abrindo espaço, além disso, para a percepção de zonas de instabilidade no processo de constituição das memórias, permitindo, desse modo, que sejam observadas as diversas ocorrências da palavra tempo em sua multiplicidade de usos e, consequentemente, de sentidos.

Tal aspecto, remetendo ao que se convencionou chamar de paradigma indiciário (GINZBURG, 1989), permitirá: a) a observação daqueles indícios que, localizados tanto em um nível textual, quanto em um nível discursivo, evidenciam não somente os diversos tipos de contato das escreventes com outros gêneros discursivos, mas também os vestígios da constituição heterogênea do gênero memórias, sobretudo no tocante aos seus pontos de ruptura, isto é, àquelas fissuras constitutivas que, inscritas em sua configuração textual-discursiva, parecem colocar em evidência o convívio, nos textos produzidos pelas escreventes, entre os traços estáveis e instáveis dos gêneros discursivos; e b) uma vez que, para essa perspectiva metodológica, "comparar quer dizer, então, fazer dialogar" (HEIDMANN, 2010, p. 82), a utilização desses princípios metodológicos comparativos permite observar as várias formas de diálogo que as professoras estabeleceram com o material que Ihes serviu de pretexto para a escrita das memórias ${ }^{6}$, possibilitando, desse modo, apreender nessas relações dialógicas uma das razões para o surgimento, no que diz respeito ao modo de constituição das memórias, da dinâmica entre os aspectos estáveis e instáveis no processo de produção do referido gênero discursivo.

5 Com efeito, Heidmann (2010) utiliza-se de tal metodologia na análise das variações genéricas existentes entre textos literários traduzidos de uma língua para outra, bem como para a análise de traduções, as quais, ainda segundo a autora, sempre se configuram como outro tipo de enunciação.

6 Refiro-me, aqui, ao fato de as professoras, antes da produção propriamente dita de seus textos, terem tido acesso a um conjunto de excertos memorialísticos, dentre os quais alguns da esfera literária, que assumiram um caráter modelar do gênero que elas deveriam produzir. 


\section{0 tempo das memórias: um percurso assentado no instável}

Neste item, partindo do uso que as escreventes fizeram da palavra tempo, analisarei o modo por meio do qual diferentes formas de inscrição do tempo se imprimiram no processo de escrita das memórias, o que, do ponto de vista que venho assumindo, representa uma singular forma de percepção de alguns aspectos da instabilidade genérica. Depreensível dos textos representativos de nosso corpus, assumo este aspecto como o resultado de um funcionamento característico inscrito na constituição deste gênero: o diálogo estabelecido entre o passado e o presente.

Apresento, de início, um quadro que contempla a totalidade de ocorrências dessa palavra, bem como os diferentes traços semânticos a ela associados pelas escreventes:

Tabela 1. Traço semântico e número de ocorrências da palavra tempo no corpus

\begin{tabular}{c|c|c}
\hline Traço semântico & Número de ocorrências & Porcentagem \\
\hline Rastro de história, fato ocorrido & 18 & $38,29 \%$ \\
\hline Delimitação cronológica & 10 & $21,27 \%$ \\
\hline Dimensão física & 06 & $12,76 \%$ \\
\hline Indefinição & 05 & $10,63 \%$ \\
\hline Permanência/continuidade & 05 & $10,63 \%$ \\
\hline Contiguidade/simultaneidade & 03 & $6,38 \%$ \\
\hline Total de ocorrências & 47 & $100 \%$ \\
\hline
\end{tabular}

Fonte: Elaboração própria

Inicialmente, a visualização do quadro permite aferir que não apenas foi significativo o uso relativamente estável que as escreventes fizeram da palavra tempo, mas que também diversos foram os sentidos a partir dos quais essa palavra emergiu no fio textual-discursivo das memórias, o que nos permite um primeiro modo de percepção da instabilidade no processo de escrita do gênero. Essa recorrência, ao apontar para a relação existente entre o uso de certas palavras e um dado gênero discursivo, parece refletir as impressões de Stella (2005, p. 181), para quem "as palavras, ao constituírem o projeto discursivo, possuem, em seu bojo, traços que permitem sua utilização, de acordo com determinado gênero, em determinada situação".

Tomemos, pois, um primeiro caso para análise. 
1. "Minha professora era muito rígida do tempo da palmatória" (T.09).

No exemplo, representativo de 38,29\% das ocorrências, o uso da palavra remete a um tempo histórico que, embora não delimitado de forma rigorosa, permite ao interlocutor a construção de sentidos vinculados a uma determinada prática de ensino marcada pela utilização de métodos baseados na violência e no autoritarismo do professor. A própria organização sintática do enunciado possibilita essa aproximação entre método de ensino e sua correspondente truculência, na medida em que a escrevente não promove nenhuma separação entre os sintagmas "muito rígida" e "do tempo da palmatória", os quais parecem formar um único e indistinto bloco significativo, como se tudo pertencesse à mesma massa temporal amorfa.

Além disso, a inscrição da expressão "tempo da palmatória", ao permitir o acesso a um estrato da própria história da escrevente, produz, em seu leitor, um duplo efeito de sentido: de distanciamento, já que a referida prática é situada num recorte de longa duração temporal - com efeito, fez parte da infância da escrevente -, mas também de aproximação, uma vez que ela, ao trazer essa prática para dentro da escrita do gênero - e, principalmente, para um curso de formação de professores -, promove sua (re) atualização sob a forma de um olhar que, ao colocar determinada prática punitiva em xeque, tornando-a obsoleta ao olhar contemporâneo, impõe um afastamento crítico da expressão, deslocada no tempo e no espaço, na mesma medida em que assume, por assim dizer, um caráter de exemplaridade aos leitores do curso de capacitação.

Vejamos outro exemplo em que acontece algo um pouco diferente:

2. "[...] sinto saudades do tempo da saia azul" (T.17).

Aqui, a palavra tempo também é trazida para o texto carregada de uma história que remonta às diferentes formas de vestimenta escolar características de uma dada época, cuja inscrição no texto permite uma identificação quase palpável do fato referido pela escrevente. Nota-se, neste exemplo, um efeito de sentido de saudosismo em relação a uma época distanciada no plano temporal, mas também espacial, já que esse sentimento saudosista ressurge logo adiante, quando ela recorda sentir falta da "lancheira e das brincadeiras do recreio". Ademais, a fluidez quanto ao uso desse sentido da palavra tempo também se encontra no fato de ela remeter a um evento cujos limites, embora esgarçados no tempo e no espaço, por assim dizer imprecisos, possibilitam, no presente e em contrapartida, o reencontro da escrevente com essa voz pretérita que constituiu parte significativa de sua história.

A seguir, apresento um caso em que a ocorrência dessa palavra estabeleceu uma tentativa de relação com limites temporais mais precisos. Vejamo-lo: 
3. "Até o tempo do recreio dos que estavam atrasados era diminuído" (T.36).

No exemplo, observa-se uma circunscrição temporal que restringe a palavra tempo a um limite mais preciso. Trata-se de um tempo específico - regulado (adestrado?) pelo relógio - em que as crianças, deixando a imobilidade da sala de aula, brincam, conversam e correm livremente, em geral no pátio das escolas. De início, o exemplo permite observar o modo como um aspecto específico da palavra tempo - seu traço cronológico - faz circular, no plano temático, uma voz de oposição a uma prática de ensino que, arbitrária, impunha restrições a um dos momentos mais aguardados pela criança na escola.

O traço de permanência, no presente, desse evento a que a escrevente se refere - com efeito, os recreios não são as "saias azuis" do passado, que já não existem mais -, atrelado a seu curto tempo de duração - um simples relógio é capaz de mensurar seu transcurso -, talvez explique sua possibilidade de circunscrição cronológica nas memórias, de vez que tais eventos são mais afeitos a períodos de curta duratividade. O que, no limite, ajudaria a explicar por que, normalmente, não se mede em minutos ou em horas o fim de uma guerra ou o tempo que separa um casal de namorados do instante correspondente a seu primeiro beijo. Além disso, outro aspecto presente no exemplo é a profunda imbricação existente entre o espaço referido pela escrevente em suas memórias - o recreio - e seu decurso, o que, de fato, confirma as impressões de Bakhtin (2003, p. 245), que, a propósito do conceito de cronotopo, observa que "em todos os seus momentos essenciais o tempo está localizado em um espaço concreto, que nele se marca".

O exemplo que mostro, a seguir, corresponde àquelas ocorrências (06) em que a palavra tempo assumiu um traço semântico de algo inapreensível, quase localizado no plano ficcional. Observemo-lo:

\section{4. "Mas o tempo, não voltava atrás" (T.77).}

No exemplo, há na ocorrência da palavra tempo um traço de intangibilidade correspondente ao gesto (impossível) de refrear os efeitos do tempo, enquanto estrutura física - sobre os desígnios humanos. Em seu texto, a escrevente utiliza a palavra numa passagem em que relembra a morte do pai, evento ocorrido na mesma época da infância, bem como o desejo - imponderável - de "ressuscitar a figura masculina". A barreira intransponível e compacta que esse tempo representa pode ser apreendida na própria forma com que a escrevente, ao utilizar-se de uma vírgula, estabelece uma cisão entre a palavra e a correspondente impossibilidade de seu retorno, aspecto materializado não somente na estruturação sintática do enunciado, mas também em seu acento prosódico que, ao definir uma ligeira pausa diante da palavra tempo, parece representar uma vã tentativa de impedir os efeitos de sua passagem. 
Vejamos, ainda, outro exemplo em que essa espessura de difícil apreensão parece atingir seu paroxismo no caráter ficcional que se Ihe associa:

5. "Faço uma viagem no tempo e retorno aos meus 5 anos de idade" (T.65).

Ficcionalizada pela escrevente, o que parece trazer ecos de sua convivência com narrativas ficcionais, a palavra tempo, no exemplo acima, assume uma dimensão imaginária e fantasiosa, cujo principal efeito é criar a ilusão de um efetivo retorno ao passado. Tratase, ainda, daquele tempo de amplitude onírica, de universal espessura, mas que é trazido pela escrevente a partir de um recurso estilístico que suaviza seu impacto sobre a impossibilidade humana de abarcá-lo por completo. Desse modo, ao ficcionalizá-lo, isto é, ao trazer esse tempo para uma dimensão que simula a transfiguração de certa realidade, a escrevente relativiza suas fronteiras, rompendo-as simbolicamente e tornando o tempo mais tangível, se não de modo concreto, ao menos possível no plano da imaginação?.

A própria forma de apresentação de seu texto permite aprimorar essa leitura, na medida em que a escrevente apresenta suas memórias mediante a cenografia (MAINGUENEAU, 2008) de uma carta pessoal - gênero este que emerge das memórias sob a forma de ruína, isto é, como "parte mais ou menos informe de outros gêneros discursivos" (CORRÊA, 2006, p. 209) -, gênero ancorado, pelas próprias condições de produção em que se realiza, num distanciamento marcado duplamente no espaço e no tempo. Assim, não somente a palavra tempo traz as marcas desses contornos ficcionais, como também o próprio gênero produzido pela escrevente, ao marcar o convívio de diferentes vozes discursivas advindas do contato com outros enunciados genéricos, aponta para esse domínio fluido em que elementos do imaginário convivem com o real no processo de escrita das memórias, instabilizando-o.

Por fım, a utilização de formas verbais no presente, isto é, naquele tempo que "situa o acontecimento como contemporâneo do instante do discurso mencionado" (BENVENISTE, 1989, p. 73), produz um efeito de afastamento no tempo - ruptura ainda mais acentuada pela metáfora da viagem proposta pela escrevente -, uma vez que essas formas, ao estabelecerem a inscrição de limites temporais distintos, projetam no discurso das memórias uma linha ilusória que, fincada no presente, aponta em direção ao passado. Percebe-se, aqui, portanto, um movimento diferente, e instável, quanto à utilização do referido tempo verbal, já que, ao invés de trazer o passado por meio de um efeito de presentificação, é o presente que, ao encenar um movimento possível apenas no plano da linguagem, projeta-se em busca das brumas desse passado.

7 Explorada à exaustão pela indústria cinematográfica, essa dimensão de tempo foi tematizada em diversos filmes, por exemplo, De volta para o futuro (1985) e Efeito borboleta (2004). 
A observação das ocorrências da palavra tempo permitiu, ainda, circunscrever outro traço semântico: o de indefinição. Este modo de inscrição, embora pouco representativo no conjunto de textos do corpus - na medida em que apenas 10,63\% das ocorrências atestaram sua presença -, também serviu como percepção dos diferentes modos de acesso das escreventes à dimensão temporal presente no processo de escrita das memórias.

Observemos um exemplo:

6. "Pouco tempo depois, pedi para ir à escola" (T.62).

Aqui, a tentativa por parte da escrevente de agarrar o tempo pelas bordas, a fim de não permitir que ele escape por entre os dedos ou que, pelo menos, não se distancie muito de certo controle, ainda que fugidio, esbarra na própria dificuldade em delimitá-lo, em circunscrevê-lo a partir de limites temporais mais precisos, o que pode ser observado pelo recurso que a escrevente faz a uma marca formal - o pronome indefinido "pouco" que acentua a vagueza, bem como a própria impossibilidade de definição do transcurso temporal. Esse tempo, de contornos imprecisos, marcadamente prosaico e típico do trânsito da escrevente com gêneros orais, pode ser apenas reconstituído às apalpadelas, de forma aproximativa e incerta. Trata-se de um tempo que, também arisco ao poder da memória, somente pode ser trazido para o processo de escrita do gênero por suas beiradas vacilantes, feitas de indeterminadas e instáveis fronteiras.

A presença da palavra tempo nas memórias também marcou a ideia de permanência, de continuidade. Nestes casos, que cobriram 10,63\% das ocorrências, o emprego da palavra mostrou outro modo de observar a materialização do tempo. Vejamos um exemplo ilustrativo deste tipo de ocorrência:

\section{7. "Ficava muito tempo treinando [...]" (T.06).}

No exemplo, a escrevente faz referência a um momento de sua vida escolar em que ela se punha a ler os textos da cartilha, a fim de decorar as lições para o dia seguinte. As lembranças desses momentos são tão marcantes que ela chega a revelar que "curiosamente o que mais me recordo são os momentos em que estudava a lição em casa". Não se trata, desse modo, de uma simples recordação de infância, mas sim de algo que traz em seu interior um traço imarcescível associado ao que não se apaga. A própria presença da marca formal de gerúndio ("treinando") sugere um efeito de sentido de algo que se quer perene, congelado num tempo que, no plano discursivo, jamais se encerra. Elástico, infinitamente distendido, esse tempo se imprime no processo de escrita das memórias, deixando-Ihe marcas indeléveis e revelando a persistência e o inacabamento daquilo que ainda parece manter-se vivo no presente. 
Um último aspecto associado à presença da palavra tempo nas memórias refere-se a uma forma de inscrição que correspondeu a apenas 6,38\% das ocorrências. Trata-se dos casos em que, ao uso da referida palavra, associou-se um traço de contiguidade, de simultaneidade. Mostro um exemplo emblemático deste tipo de ocorrência:

\section{8. "Ao mesmo tempo que as coisas fluíam naturalmente" (T.13).}

No exemplo, a escrevente refere-se à simultaneidade de dois eventos que, conjugados, inscrevem-se no processo de escrita das memórias: a entrada para a escola, com tudo que isso traz de expectativa, e a presença de uma professora "muito rígida [...] muito brava". Longe, porém, de apontarem para uma mesma direção, como o fluxo de dois rios que seguissem cursos contrários, a coexistência desses diferentes tempos marca também o convívio de diferentes e simultâneas formas de inserção no próprio universo escolar, na medida em que, ao lado de expectativas agradáveis, podem encontrar-se, igualmente, os dissabores advindos da figura austera de uma professora. A palavra tempo, neste caso, remete, portanto, à confluência de diferentes durações temporais que, imprimindo formas distintas de percepção do tempo no espaço escolar, também deixaram os traços de sua permanência no processo constitutivamente instável das memórias.

\section{Considerações finais}

Procurei mostrar, a partir da análise de diferentes usos que professoras fizeram da palavra tempo, algumas formas de percepção da instabilidade genérica presente no processo de constituição do gênero memórias. No caso específico dos exemplos trazidos para análise, parece encontrar-se nesse aspecto constitutivo e fundamental do gênero - 0 diálogo entre o passado e o presente - o motor que impulsiona as diferentes formas de inscrição e percepção do tempo, cuja heterogeneidade, ao materializar-se na escrita das memórias, colocou em cena algumas das possibilidades para sua apreensão.

Além disso, os textos analisados puseram em evidência os percursos que atestam o constante diálogo entre a mudança e a permanência, entre a repetição e a variação (numa palavra, entre o que parece permanecer, mas, ao mesmo tempo, escapar), elementos estes sempre presentes no modo heterogêneo de constituição do gênero produzido pelas professoras. No limite, tal aspecto evidencia a dinâmica constitutiva entre estabilidade e instabilidade no processo de produção de um gênero discursivo.

Dizendo de outro modo, a própria existência dos "tipos relativamente estáveis de enunciados" (BAKHTIN, 2003, p. 262) só tem sentido, ao que parece, se forem consideradas as relações estabelecidas entre os aspectos estáveis dos gêneros discursivos (suas forças centrípetas) e seus aspectos instáveis (suas forças centrífugas), os quais não apenas atestam o diálogo intergenérico, como também apontam para determinados 
pontos de ruptura dentro do próprio gênero. Em outras palavras, os gêneros do discurso, bem como sua apropriação pelo discurso pedagógico, só ganham vida a partir da tensão e da dinâmica constitutivas que, dotando-os de forma e sentido, contribuem, a um só tempo, para abrir frinchas em sua estabilidade sempre fluida e cambiante, aspecto que procurei salientar na consideração da natureza constitutivamente instável presente no processo de escrita do gênero produzido pelas professoras.

\section{REFERÊNCIAS}

AMORIM, M. Cronotopo e exotopia. In: BRAIT, B. (org.). Bakhtin: outros conceitos-chave. São Paulo: Contexto, 2008. p. 95-113.

BAKHTIN, M. Questões de literatura e de estética: a teoria do romance. São Paulo: Hucitec Editora, 2014.

BAKHTIN, M. Estética da criação verbal. São Paulo: Martins Fontes, 2003.

BENVENISTE, E. A linguagem e a experiência humana. In: BENVENISTE, E. Problemas de linguística geral II. Campinas: Pontes, 1989. p. 60-80.

CÁLIS, O. G. T. Quando as memórias são a matéria: memórias de professoras alfabetizadoras e instabilidade genérica. 2015. Tese (Doutorado em Letras) - Faculdade de Filosofia, Letras e Ciências Humanas, Universidade de São Paulo, São Paulo, 2015.

CORRÊA, M. L. G. Relações intergenéricas na análise indiciária de textos escritos. Trabalhos de Linguística Aplicada, Campinas, v. 45, n. 2, p. 205-224, jul./dez. 2006.

FARACO, C. A. Linguagem e diálogo: as ideias linguísticas do círculo de Bakhtin. São Paulo: Parábola Editorial, 2009.

FIORIN, J. L. Introdução ao pensamento de Bakhtin. São Paulo: Ática, 2008.

GINZBURG, C. Mitos, emblemas, sinais: morfologia e história. São Paulo: Companhia das Letras, 1989.

HEIDMANN, U. Comparatismo e análise de discursos: a comparação diferencial como método. In: RODRIGUES, M. G. S.; NETO, J. G. S.; PASSEGGI, L. (org.). Análises textuais e discursivas: metodologia e aplicações. São Paulo: Cortez, 2010. p. 61-82. 
MAINGUENEAU, D. Cenas da enunciação. São Paulo: Parábola Editorial, 2008.

PÊCHEUX, M. O Discurso: estrutura ou acontecimento. Campinas: Pontes, 2002.

STELLA, P. R. Palavra. In: BRAIT, B. (org.). Bakhtin: conceitos-chave. São Paulo: Contexto, 2005. p. 177-190. 